\title{
COVID-19 Lockdown and Physical Activity: How Do Sexes React?
}

\author{
Christos Konstantinidis ${ }^{1}$, Doukas Konstantoulas ${ }^{1}$, Evangelos Bebetsos ${ }^{1 *}$, George Bebetsos ${ }^{1}$
}

${ }^{1}$ Democritus University of Thrace, Komotini, GREECE

*Corresponding Author: empempet@phyed.duth.gr

Citation: Konstantinidis, C., Konstantoulas, D., Bebetsos, E., \& Bebetsos, G. (2021). COVID-19 Lockdown and Physical Activity: How Do Sexes React?. Aquademia, 5(1), ep21007. https://doi.org/10.21601/aquademia/10808

\section{ARTICLE INFO}

Received: 1 Nov. 2020

Accepted: 21 Dec. 2020

\begin{abstract}
According to the World Health Organization, the spread of the COVID-19 pandemic raises concerns about increased panic and increased anxiety in people who are trapped in either a real or a theoretical coronavirus threat. This preliminary study aimed to investigate how adults cope with a pandemic lockdown concerning Physical Activity. The sample consisted of 904 people, 417 men, and 487 women. The participants completed the Greek revised version of the "Planned Behavior Theory" questionnaire. ANOVA analyses revealed that men increased their physical activity involvement but on the contrary, women decreased theirs. Overall, results identified the importance of recording adult intentions for PA in a state/period of incarceration and its important role for the future shaping of health behaviors.
\end{abstract}

Keywords: pandemic, planned behavior theory, physical activity, sexes

\section{INTRODUCTION}

During the outbreak of the COVID-19 pandemic, more than a quarter of the world's population experienced compulsory home confinement to slow the spread of the disease (Cheval et al., 2020; Mudenda et al., 2020). It is already known that the COVID-19 pandemic is highly likely to have affected people's regular physical activity as well as their standard of living. This happens for both practical and emotional reasons. Initially, restrictive measures, such as the closure of gym clubs and sports venues, restricting the movement of the general public, have dramatically disrupted people's daily routines (Boberska et al., 2018; Fitbit Staff, 2020).

Although in the social sector the effects of lockdown are immediately apparent, such as the flourishing of internet conferences and the possible reduction in physical activity due to travel bans, the management of extended leisure time and the behaviors that develop in it are not a familiar research area (Drewes, Daumann, \& Follert, 2020; Cheval et al., 2020). Increasing potential leisure time can be an opportunity to promote a more active lifestyle, but it can also encourage sedentary activities. Given their role in human health, understanding whether changes in physical activity and sedentary behaviors are due to the onset of COVID-19 is considered essential (Cheval et al., 2020; Rogers et al., 2020).

In the past, numerous theories have been used to explain why people choose specific behaviors, including the "Theory of Planned Behavior". According to the theory, what precedes any behavior is the "Intention" of the individual to take some action (Ajzen, 2012). The stronger a person's intention, the more likely they are to behave according to their behavioral predisposition (Ajzen \& Fishbein, 1980).

Intention is determined by a combination of two factors: (a) attitude towards behavior (positive or negative predisposition to behavior) and (b) subjective rules (social pressure that can be exerted on the individual regarding the execution of behavior). Besides, it is reported that two types of beliefs influence behavior: (a) behavioral beliefs, which influence attitudes toward behavior, and (b) regulatory beliefs, which suggest the social factor. The combination of the individual's attitude towards behavior and subjective rules determines his intention to display behavior or not (Ajzen, 2011).

A behavior can be ultimately under the control of the individual (absolutely controlled by the individual), i.e., decide (consciously) to implement it or not (Ajzen \& Fishbein, 1980). But regardless of a person's intention to display a behavior, there are usually obstacles that can create problems. These barriers are internal factors such as skills, knowledge, planning, and external factors such as time, opportunities, working with others, etc (Ajzen, 2011).

Few studies have investigated gender within the TPB and physical activity. One study that investigated TPB relationships among children reported that gender did not show a relationship with physical activity or intention (Rhodes, Macdonald, \& McKay, 2006). Similarly, a large population sample showed that TPB belief- PA behavior correlations were invariant across genders (Rhodes, Blanchard, \& Blacklock, 2008). 
Table 1. N of people participating in PA before and during lockdown

\begin{tabular}{|c|c|c|c|c|}
\hline & \multicolumn{4}{|c|}{ Before Lockdown } \\
\hline & \multicolumn{2}{|c|}{ Not Involved } & \multicolumn{2}{|c|}{ Involved } \\
\hline Men & 256 & $61 \%$ & 161 & $39 \%$ \\
\hline \multirow[t]{3}{*}{ Women } & 287 & $59 \%$ & 200 & $41 \%$ \\
\hline & \multicolumn{4}{|c|}{ During Lockdown } \\
\hline & \multicolumn{2}{|c|}{ Not Involved } & \multicolumn{2}{|c|}{ Involved } \\
\hline Men & 196 & $47 \%$ & 221 & $53 \%$ \\
\hline Women & 345 & $71 \%$ & 142 & $29 \%$ \\
\hline
\end{tabular}

Noting the absence of research regarding the relationship of PA and its relation to gender in times of pandemic in Greece and internationally, this research is an attempt to record if adult attitudes and intentions regarding their involvement (or not) to PA changed due to COVID-19 first lockdown period, in Greece.

\section{METHODS}

The sample consisted of 904 individuals, 417 men (46.2\%), and 487 women (53.8\%), between the ages of 18 and 70 years $(M=36.26, S D=12.48)$. All subjects completed the Greek modified version (Theodorakis, 1994) of an anonymous questionnaire based on the "Theory of Planned Behavior" (Ajzen \& Fishbein, 1980).

The sample completed the questions concerning the "Intention" factor.

\section{More specifically:}

Intention was estimated by the mean score of the responses to three different questions: "I intend/I will try/ I am determined to exercise regularly for the next 2 months" Responses to the first question (I intend...) were rated on a 7point scale from $1=$ very unlikely to 7 =very likely. A 7 -point scale with endpoints labeled $1=$ definitely no to $7=$ definitely yes was used for the other two questions.

Additionally, the sample indicated if they were exercising before and during the pandemic lockdown, by providing a "Yes" or "No" answer (Table 1).

Research data was collected using an electronic form / questionnaire (Google Form), as the researchers considered its use mandatory in compliance with the new Coronavirus protection rules (COVID-19), avoiding unnecessary physical contact. Data collection period lasted two months (April-May 2020). The reason for selecting the specific period is related to the duration of the outbreak of COVID-19 and its mandatory inclusion, in Greece.

\section{RESULTS}

The internal consistency of the factor was .91.

In continuation, ANOVA analyses were conducted to find any differences among sexes' previous (before lockdown) and current (during lockdown) physical activity/exercise level. The analyses revealed the following statistically significant differences: (a) For Men: $F_{1,902}=5549, \mathrm{p}<.001$. More specifically, their initial physical activity involvement was $(M=1.01, S D=.302)$, which was increased during lockdown $(M=1.26, S D=1.0=72)$.

(b) For Women: $F_{1,902}=7174, \mathrm{p}<.001$. More specifically, their initial physical activity involvement was $(M=1.21, S D=.305)$, which was decreased during lockdown $(M=1.11, S D=.319)$.

\section{DISCUSSION}

Results of the study underlined the critical role of COVID19 on physical activity and exercise in general. As previous studies mentioned home confinement could dramatically impact lifestyle activities, including participation in sports and PA engagement (Ammar et al., 2020; Neto et al., 2020). More specifically, in Greece women seem to be more susceptible, compared to men. As findings suggest they are more prone to stress-related disorders such as post-traumatic stress disorder and anxiety disorders (Voitsidis et al., 2020). In the above category, although not listed as a disorder, a notably stressful condition that has occurred very recently is lockdown because of COVID-19. Women's vulnerability appeared here as well, as women turned out to be less involved with PA during the quarantine. One reason that may explain this difference, which has already been proven (Shaw, Liang, Krause, Gallant, \& McGeever, 2010), is the different physical illnesses they exhibit and the different perceptions of genders about how to manage their illnesses. For example, arthritis in women is a disease that urges them to lead a sedentary life and not exercise. Quarantine is a great opportunity for leisure time.

Also, Greece is a country with a more traditional mentality and the family structure is based on older stereotypes between the genders (Paraskevopoulos, Bezevegis, \& Giannitsas, 1998). The mother usually takes care of the house, feeding and cleaning the family members on a daily routine. As family members spend more hours of the day in the home, the responsibilities of the "housewife" increase. More meals, more clutter, occupy children during the daily time, opportunities for housework that they did not have time to do previously, or more hands are needed, are just some of these changes. This fact operates inversely depending on the free time left for the caregiver to pursue with the PA.

Another sociological reason for gender differences in the psychological need, perhaps emotional guilt, of women to make up for the lost family time. As the modern way of life requires the woman to sacrifice many hours for the benefit of her professional development, this fatally implies the deduction of hours from her involvement with her family (Giota, 2015). 
Finally, another fact that must be considered concerning this difference, is the subjective opinion of the respondents about what they consider PA Although the definition of PA became completely clear before completing the questionnaires, based on the answers it appeared that the participants have a subjective view of what activities they rank in the PA, but also which ones eliminate. Of course, this phenomenon is not Greek originality, as it is found in another research (Hallal \& Siqueira, 2004; Hallal, Victora, Wells \& Lima, 2003), which strengthens the hypothesis of researchers.

Considering all the above reasons, it is a logical result to reduce the preoccupation with $\mathrm{PA}$, which is widely used as an antidote to anxiety and stress.

However possible limitation of the present investigation should be discussed. The investigation took place during the first lockdown in Greece. In conclusion, these findings may contribute to the management of PA and its critical role, during the COVID-19 pandemic. Professionals may take into consideration the exquisite aspects that affect directly individual lives.

Author contributions: All co-authors have involved in all stages of this study while preparing the final version. They all agree with the results and conclusions.

Funding: No external funding is received for this article.

Declaration of interest: The authors declare that they have no competing interests.

Ethics approval and consent to participate: Not applicable. Availability of data and materials: All data generated or analyzed during this study are available for sharing when appropriate request is directed to corresponding author.

\section{REFERENCES}

Ajzen, I. (2011). Behavioral interventions: Design and evaluation guided by the theory of planned behavior. In $\mathrm{M}$. Mark, S. I. Donaldson, \& B. Campbell (Eds.), Social Psychology and Evaluation (pp. 72-97). N.Y.: The Gilford Press.

Ajzen, I. (2012) Handbook of theories of Social Psychology. London, UK: Sage.

Ajzen, I., \& Fishbein, M. (1980). Understanding Attitudes and predicting social behavior. Englewood Cliffs, NJ: PrenticeHall.

Ammar, A., Mueller, P., Trabelsi, K., Chtourou, H., Boukhris, O., Masmoudi, L., ... Hoekelmann, A. (2020) Psychological consequences of COVID-19 home confinement: The ECLBCOVID19 multicenter study. PLoS ONE, 15(11), e0240204. https://doi.org/10.1371/journal.pone.0240204

Boberska, M., Szczuka, Z., Kruk, M., Knoll, N., Keller, J., Hohl, D. H., \& Luszczynska, A. (2018) Sedentary behaviours and health-related quality of life. A systematic review and meta-analysis. Health Psychology Review, 12(2), 195-210. https://doi.org/10.1080/17437199.2017.1396191

Cheval, S., Mihai Adamescu, C., Georgiadis, T., Herrnegger, M., Piticar, A., \& Legates, D. R. (2020) Observed and Potential Impacts of the COVID-19 Pandemic on the Environment. International Journal of Environmental Research and Public Health, 17, 4140. https://doi.org/10.3390/ijerph17114140
Drewes, M., Daumann, F., \& Follert, F. (2020) Exploring the sports economic impact of COVID-19 on professional soccer. Soccer \& Society, 22(1-2), 125-137. https://doi.org/10.1080/14660970.2020.1802256

Fitbit Staff. (2020) The impact of coronavirus on global activity. Fitbit News, 2020. https://blog.fitbit.com/covid-19-globalactivity/

Giota, M. (2015). Views and perceptions of young people about the roles of the two sexes in the family and society (Unpublished Undergraduate Thesis). School of Economy and Administration, Kavala, Greece.

Hallal, P. C., \& Siqueira, F. V. (2004) Compliance with vigorous physical activity guidelines in Brazilian adults: prevalence and correlates. Journal of Physical Activity and Health, 1(4), 389-397. https://doi.org/10.1123/jpah.1.4.389

Hallal, P. C., Victora, C. G., Wells, J. C. K., \& Lima, R. C. (2003) Physical inactivity: prevalence and associated variables in Brazilian adults. Medicine \& Science in Sports \& Exercise, 35(11), 1894-1900. https://doi.org/10.1249/01.MSS. 0000093615.33774.0E

Mudenda, S., Zulu, A., Phiri, M. N., Ngazimbi, M., Mufwambi, W., Kasanga, M., \& Banda, M. (2020) Impact of Coronavirus Disease 2019 (COVID-19) on College and University Students: A Global Health and Education Problem. Aquademia, 4(2), ep20026. https://doi.org/10.29333/ aquademia/8494

Oliveira N., Elsangedy, H. M., Tavares, V. D. O., Teixeira, C. V. L. S., Behm, D. G., Da Silva-Grigoletto, M. E. (2020) \#Training in Home - training at home during the COVID19 (SARS-CoV-2) pandemic: physical exercise and behavior-based approach. Revista Brasileira de Fisiologia do Exercício, 19(2supl), S9-S19. https://doi.org/10.33233/ rbfe.v19i2.4006

Paraskevopoulos, I., Bezevegis, I., \& Giannitsas, N. (1998) Transgender Relationships. Hellenic Letters Pubs. Athens.

Rhodes, R. E., Blanchard, C. M., \& Blacklock, R. E. (2008). Do physical activitybeliefs differ by age and gender? Journal of Sports and Exercise Psychology, 30, 412-423. https://doi.org/10.1123/jsep.30.3.412

Rhodes, R. E., Macdonald, H. M., \& McKay, H. A. (2006). Predicting physical activity intention and behaviour among children in a longitudinal sample. Social Science and Medicine, 62, 3146-3156. https://doi.org/10.1016/ j.socscimed.2005.11.051

Rogers, J. P., Chesney, E., Oliver, D., Pollak, T. A., McGuire, P., Fusar-Poli, P., Zandi, M. S., Lewis, G., \& David, A. S. (2020) Psychiatric and neuropsychiatric presentations associated with severe coronavirus infections: a systematic review and meta-analysis with comparison to the COVID-19 pandemic. Lancet Psychiatry, 7, 611-627. https://doi.org/10.1016/S2215-0366(20)30203-0

Shaw, B. A., Liang, J., Krause, N., Gallant, M., \& McGeever, K. (2010) Age differences and social stratification in the longterm trajectories of leisure-time physical activity. Journals of Gerontology Series B: Psychological Sciences and Social Sciences, 65(6), 756-766. https://doi.org/10.1093/geronb/ gbq073 
Theodorakis, Y. (1994) Planned behavior, attitude strength, self-identity, and the prediction of exercise behavior. The Sport Psychologist, 8, 149-165. https://doi.org/10.1123/ tsp.8.2.149
Voitsidis, P., Gliatas, I., Bairachtari, V., Papadopoulou, K., Papageorgiou, G., Parlapani, E., Syngelakis, M., Holeva, V., \& Diakogiannis, I. (2020) Insomnia during the COVID-19 pandemic in a Greek population. Psychiatry Research, 289, 113076. https://doi.org/10.1016/j.psychres.2020.113076 